\title{
A Review \\ Drought stress and its impact on plant mechanism
}

\author{
Anjali Tiwari, Shailaja Punetha and Kapil Kesarvani
}

\begin{abstract}
SUMMARY
Drought is one the most common adverse environmental problem is increasing as a result of increasing population of world and intensive use of natural resources. Drought stress has major constraints to agricultural productivity worldwide, particularly in warm, arid and semi-arid areas. It adversely affects plants Morphological, Physiological and Biochemical processes and prolonged drought stress limits plant growth and productivity. The effect of drought stress at a whole plant level results non-normal physiological process that impact one or a combination of biological and environmental factors. That is why this review paper is mainly focused on recent information about the influence of water stress on plants, as well as its mechanisms of adaptation. It is shown that plants have evolved physiological and biochemical adaptations to cope with water stress. Plant used molecular mechanism to increase tolerance against drought are discussed. The literature analysed in this review shows an understanding of how these systems are regulated and upgrade the effect of drought stress on plants mechanism. The provided information needed to improve plants tolerance against drought stress by using biotechnological tools.
\end{abstract}

Key Words : Drought stress, Morphology, Physiology, Photosynthesis, Adaptation

How to cite this article : Tiwari, Anjali, Punetha, Shailaja and Kesarvani, Kapil (2021). Drought stress and its impact on plant mechanism. Internat. J. Plant Sci., 16 (AAEBSSD): 95-112, DOI:10.15740/HAS/IJPS/16.AAEBSSD/95-112, Copyright@2021: Hind Agri-Horticultural Society.

Article chronicle : Received : 10.07.2021; Accepted : 25.07.2021

$\mathrm{P}$ ants experienced mostly biotic and abiotic stresses that have a great impact on their survival. Abiotic stresses are the important environmental factors that limit the productivity of many crops and also affect

\section{$\longrightarrow$ MEMBERS OF THE RESEARCH FORUM}

Author to be contacted :

Shailaja Punetha, G.B. Pant National Institute of Himalayan Environment and Sustainable Development, Kosi-Katarmal, Almora (Uttarakhand) India

Email : shailupunetha@gmail.com

Address of the Co-authors:

Anjali Tiwari and Kapil Kesarvani, G.B. Pant National Institute of Himalayan Environment and Sustainable Development, Kosi-Katarmal, Almora (Uttarakhand) India the quality and amount of crops yield. Particularly water stress directly affects the physiology of plants, Drought is one of the most prevalent environmental stresses, defined as "a brief reduction in moisture accessibility, in which the amount of available water is significantly below normal for a set period." Its growth and productivity are harmed as a result of this situation. In rain-fed (unirrigated) area water stress is a natural phenomenon.

Abiotic stresses, such as drought, salinity, severe temperature, chemical toxicity, and oxidative stress, induce an imbalance in the normal state of the environment in the Biosphere.

Every year, environmental conditions such as water 
stressors, which are the most critical yield limiting variables for the world's food supply, have a negative impact on plant growth, development, and productivity. Abiotic stress, such as water stress, is one of the limiting reasons for crop failure and a threat to successful agricultural production. It has an impact on at every stage of their development and lead to death of the plant.

Drought is one of the key factors limiting crop output around the world, particularly in warm and dry areas. More than $50 \%$ of average crop yield of major crops are reduce by water stress. As a result, drought tolerance is an essential yield attribute. The biomass of non-woody plants, which is the central molecule in the physiological processes of plants as a whole, makes up about 80-90 per cent of water. In plant physiology, water stress is defined as a decrease in water potential and turgor.

Water stress plays a major role in reduction of crop yield. In plants, drought stress induces reduction in growth rate, stem elongation, leaf expansion, and stomatal movements. According to (Levit, 1980), abiotic stress occurs when water uptakes from soil cannot balance water loss through transpiration. Manifestation of a drought stress condition is an annual event, almost persistently. As we know that Indian agriculture is rich in millet crops, particularly in minor millets, grown extensively from temperate north Himalayan region to peninsular region. In terms of world agriculture production millets are among the important drought-resistant crops. During photosynthesis, photorespiration, and dark respiration, a plant under water stress is thought to react and produce a variety of reactive oxygen species (ROS).

According to (Tuba et al., 1996 and Sarafis, 1998), drought is defined by fundamental changes in water relations, biochemical and physiological processes, membrane structure, and ultra-structure of sub cellular organelles). To consume the water resources more resourcefully, there is a necessity to improve WUE of crops, through enabling farmers to replace calendarbased scheduling of irrigation and adopt need-based irrigation (Garg et al., 2016).

\section{What is drought stress?}

Drought is the common environmental factor that plants encountered mostly (Bonhert et al., 1995; Thomashow, 1998; Chaves et al., 2003 and Hamdy et al., 2003). Drought stresss is characterised as moderate loss of water that causes stomatal closure and restricts gas exchange. In general, Desiccation causes an excessive loss of water, which disrupts metabolism and cell structure, finally leading to the stoppage of enzymecatalyzed activities.

Drought resilience, according to (May and Mithorpe, 1962), is the ability of a crop or species to thrive satisfactorily in places where there is a recurrent water deficit. Drought-resistant plants are able to withstand or avoid the onset of severe water stress (Levitt, 1972).

Drought stress can have a significant impact on agro-ecosystems as well as on food crops. It becomes a huge problem in plant breeding procedures to improve yield under drought stress circumstances. Drought stress can be characterised by physio-biochemical changes in plants, in addition to the typical changes in plant appearance (Dong et al., 2006).

Drought stress causes a decrease in growth rate, stem elongation, leaf growth, and stomatal movement. Further more, it affects physiological and organic chemistry processes that govern plant development and productivity, limiting chemical change and as a result, plant yield (Alexieva et al., 2001).

Drought stress occurs when water intake from the soil is insufficient to offset water loss through transpiration (Levitt, 1980). When the water system to the roots gets excessively high, a plant undergoes drought stress. These circumstances typically coincide in arid and dry areas. Drought occurs in numerous parts of the world each year, usually wreaking havoc on crop output (Ludlow and Muchow, 1990). Crop production losses due to water shortages are projected to outnumber losses due to all other reasons combined (Kramer, 1983).

\section{In general, drought can be illustrated as following types:}

Types of drought :

There are three major ways to describe the drought:

- A meteorological drought caused by a lack of rainfall

- Reservoir water levels determine the severity of a hydrological drought.

- Drought in agriculture due to a lack of water for crops.

\section{Effect of climate change :}

Climate change is likely to create exaggerated temperatures across the planet reaching the high level, as $6^{\circ} \mathrm{C}$ by 2050 . As per IPCC (2007) together with some other studies, temperature is likely torise by 1.0 to $2{ }^{\circ} \mathrm{C}$.Several phenological features, such as early 
flowering and maturity, are important components of crop adaptation in locations where the growing season is limited by terminal dryness and harsh temperatures (Subbarao et al., 1995). Drought-proofing crops by producing heatresistant cultivars is one aspect of this adaptation approach for millet crops as the world warms (Kurukulasuriya et al., 2006 and Benhin, 2008). With the disappearance of many landraces from their natural habitats, according to (Bonham et al., 2010), a cohesive and cost-effective system of germplasm development and exchange is necessary in order handle the wants of small-scale farmers. The tailored germplasm needs characterization and evaluation. Assessments of appropriate and accessible genetic resources required to seek ways and means to deal with these stresses enable agricultural systems to adapt to dynamic environments (Ainsworth et al., 2008; Bonham et al., 2010; Jarvies et al., 2011 and Newton et al., 2011).

\section{A biological state that could be stressful for one plant could be ideal for another:}

The most common definition of biological stress is an adverse force or circumstance that interferes with a biological system's normal functioning and health, such as plants (Jones and Jones, 1989).

Environmental stresses provoke various plant responses, variable from altered organic phenomenon to metabolic processes. Maintaining higher plant productivity beneath environmental stresses is credibly a challenge facing trendy agriculture (Gill and Tuteja, 2010). Among the environmental stresses, drought could be a major abiotic stress limiting agricultural crop production and is the most vital stresses worldwide (Karami, 2013).

Drought, salinity, temperature extremes, nutrient shortages, and mineral toxicities are among abiotic factors that slow plant growth and reduce crop yield. Because of global climate change, land degradation and deteriorating water quality, these pressures are likely to become increasingly important (Langride et al., 2006; Munns et al., 2008; Morison et al., 2008; Wicombe et al., 2008; Salekdeh et al., 2009; Carmer et al., 2010 and White et al., 2010). Crops answer the abiotic stresses with varied modifications on the morphological, cellular, physiological, organic chemistry and molecular level (Aprile et al., 2013; Siddiqui et al., 2015 and Chou et al., 2015).

Within the last decade, variant studies targeted on the response of crops to one stress (Chew et al., 2010 and Hirayama et al., 2010). Many abiotic stresses, on the other hand, might occur at the same time and crops are constantly exposed to a combination of abiotic stresses in the field.Drought and heat stress are two of the most important abiotic factors that threaten crop development and property agriculture around the planet (Boyer et al., 1982 and Lipiec et al., 2013). Drought stress, which can be caused by a lack of rain or a lack of nutrients in the soil, can cause a variety of biochemical, physiological and genetic reactions in plants, limiting crop growth (Seki et al., 2007 and Vadez et al., 2012).

According to Pinstrup-Andersen et al. (1999), the world's population is quickly growing, with an estimated population of over 8 billion by 2025. Every year, about 100 million people are added to the current population of 6 billion people, according to this data. It is predicted that in developing countries increasing population create a serious nutritional problem at present and future. To address the challenge of rising global population and ensure the well-being of humanity, food production must increase by upto 100 per cent in the next 25 years (Borlaug and Dowswell, 1993). Extreme climatic events have become more common in recent years and are anticipated to become more often in the near future (IPCC, 2007 and Tin, 2008). Due to the scarcity of agricultural soils, increasing food production is already possible by cultivating it on cultivated ground.

However, a new scenario implies that global production and soil fertility are declining as a result of insufficient nutrients in the soil. As a result of the world's growing population and heavy use of natural resources, environmental problems (such as water scarcity and salinity) are becoming more prevalent. Abiotic limitations are the most significant limits on plant development and output. The major constraints for plant growth and productivity are abiotic stresses. To overcome these abiotic stresses plants, adapt several resistance mechanisms like, maintaining root and higher tissue water status through showing certain leaf characters.

\section{Impact of drought stress on plants:}

On Earth, the usable area is categorized based on stress factors, with drought stress accounting for around $26 \%$ of the total, followed by mineral stress $(20 \%)$, cold and freeze stress (15\%), and other stresses (29\%) whilst $10 \%$ are not exposed to any of the stress factors (Yasemin and Tugce, 2005).

It has an impact on the growth, yield, and biomass of plants. As a result, drought stress is one of the most 
common environmental stresses that has a negative impact on growth and output.In plants, it causes a variety of physiological, biochemical, and molecular reactions. Therefore, as a result, stress/combination of stresses comprises both destructive and constructive elements, and thus serves as both a selection factor and a driving force for increased resistance and adaptive evolution (Larcher, 1987).

Drought is initiate as multidimensional in nature; its effects can be seen in plants at numerous stages of development. Drought also impacts plant water relations by reducing water content, turgor, total water and stomatal closure, as well as limiting gaseous exchange, lowering transpiration and carbon absorption rates. Plant developmental stages are influenced by photosynthesis, respirationtrans location, nutrient metabolism and hormones under extended drought.

\section{Effect of drought stress on morphological and physiological characteristics of plants:}

Drought affects the water relationship in plants at the cellular and whole-plant level, creating both particular and non-specific reactions, damages and adaptations (Beck et al., 2007). Plant morphological and physiological factors such as plant height, leaf area, plant weight, yield, biomass, chlorophyll content, photosynthetic pigments, and stomatal activity are all affected by drought.

Water stress plays an important role in reducing crop yield. The major limitations to agricultural productivity worldwide are water stress, mostly in arid and semi-arid parts of the world (Boyer, 1982). Water stress has a negative impact on crop from its growth stage as the length and strength of the stress (Salter and Goode, 1967). Drought has been reported in plants caused by stress spread by environmental factor which adversely affects growth as well as productivity. Growth is phenomenally influenced due to a decline in turgor pressure. Mostly water stress affects cell expansion and cell growth due to lower turgor pressure (Karthikeyam et al., 2007 and Jaleel et al., 2007). Crops are grown in a variety of environmental stresses imposing serious limitations to growth (Mahaja and Tuteja, 2005).

According to (Mansfield and Atkinson, 1990 and Meyer and Genty, 1998) drought leads to stomatal closure which directly reduces the gaseous exchange and the availability of $\mathrm{CO}_{2}$ for photosynthesis. In plants the reduced rate of photosynthesis can lead to formation of reactive oxygen species (ROS) which results a kind of oxidative stress (Loreto et al., 1995; Tezara et al., 2002).
Drought stressgenerate Stress injury and ROS which also triggers detoxification signallingby activating genes that are responsible for controlling damage and Drought causes stomatal closure, which causes. Reduced photosynthesis rates can result in the creation of reactive oxygen species (ROS) as a result of energy/electron redirection in the photosystem, resulting in oxidative stress. Stress injury and the production of reactive oxygen species (ROS) in response to stress activate genes involved in damage repair, resulting in stress tolerance (Foyer and Noctor, 2003 and Flexas et al., 2006). In plants drought imposes injury on cellular physiology therefore results metabolic dysfunction.

Drought stress reduces plant output by $50-30 \%$ due to low humidity in plant development, resulting in high evapotranspiration, and high temperature intensity, resulting in increased respiration, photosynthesis, and enzyme activities in plants (Ghodsi et al., 1998).

Plants that are resistant to water stress generate a variety of accommodating physiological and chemical responses (Dhanda et al., 2004; Serraj et al., 2004; Benjamin Nielsen, 2006; Praba et al., 2009; Hanson, Hitz 1982 and Mahajan, Tuteja 2005).

High degree water stress conjointly leads to the inhibitionof chemical change in the plants by means of inflicting pigment content changes (Iturbe-Ormaetxe et al., 1998). reported that leaf pigment content decreases due to drought stress (Ommen et al.,1999). Decrease in water-stressed pigment is especially an outcome to chloroplasts' harm due to active gas species (Smirnoff, 1995).

Water stress rice crop undergoes influences water loss. Water stress is mainly characterised by water stress and content reduction, lower leaf water potential, etc. (Jaleel et al., 2008a) (Jaleel et al., 2008a).Ion absorption, chemical change, respiration, translocation and growth stimulants are all physiological and biochemical processes that affect plant growth (Farooq et al., 2008; Jaleel et al., 2008b and Razmjoo et al., 2008). Water stress can be a limiting factor in agricultural output because it prevents crops from reaching their genetically determined theoretical yield (Begg and Turner, 1976).

\section{Effect on plants growth :}

Growth is one of the most sensitive physiological factors which is affected by reduction of turgor pressure due to drought stress.Cell growth occurs in plants only when the turgor pressure exceeds the cell wall yield threshold. Drought stress affects cell expansion and 
growth due to decreased turgor pressure, according to (Karthikeyan et al., 2007 and Jaleel et al., 2007).

Deficiency of water, impaired plant growth in pearl millet owing to drought stress (Kusaka et al., 2005). Plant needed water for growth processes. Maintaining WUE for higher metabolic state and growth potential in multifunctional agroforestry tree species (Kumar et al., 2003 and Kusaka et al., 2005) is achieved in multipurpose agroforestry tree species. Environmental stresses, such as drought, salinity, or low temperatures, are the most important constraints to crop growth (Mahajan and Tuteja, 2005).

Plants experience some signs in stressful situations, such as an irreversible and quick drop in leaf growth and shoot fresh weight (Ahmed et al., 1980 and somasundram et al., 2007). Plants use a variety of techniques in reaction to stress, which has an impact on their development and productivity (Epstein et al., 1980 and Yancey et al., 1982).

Drought is a significant determinant in plant growth, affecting both elongation and expansion growth (Anjum et al., 2003; Kusaka et al., 2005 and Shao et al., 2008). Water scarcity is one of the most significant environmental pressures affecting agricultural production and productivity around the world, resulting in yield loss.

It's been established that drought stress is incredibly vital limiting issue at the initial part of plant growth and institution. It affects each elongation and growth (Bhatt and Srinivasa, 2005; Kusaka et al., 2005 and Shao et al., 2008). During water stress condition plants leaf frequently rolls, reduces leaf area, cell size and intercellular volume. When drought stress increased in plants, the leaf temperature also increases which leads to declining stomatal and transpiration rate. Leaf attribute must be incorporated for better improvement of drought tolerance in crops. Root system is also better criteria for selection of drought tolerance line or varieties in crops. According to (Boyer, 1996) deep root system has been identified as for drought tolerance improvement. (Eghball and Maranville, 1993) drought stress caused pronounced changes in the root structure like as increasing branching and density. Under moisture stress, production of root system is very important and good correlation with yield (Darofeev and Tyselano, 1982).

Water stressed plants have a tiny root system, which results in a drop in root size that is proportionate to the amount of water stored. According to (Slayter, 1973), there are two types of effects found at the root developmental stage in water stressed conditions. The first is a reduction in meristematic and root elongation activity, which is directly related to the level of inter water and second effect found in root system is submerization of nutrient uptake.

Under water stress condition high dry weight is a desirable characteristic for persistence of the plant. According to (Farooq et al., 2009) there are some common adverse effects of water stress on crop plants such as reduction of fresh and dry biomass production. (Kage et al., 2004) also suggested that under water stressed condition plant production is strangely related to the process of the dry matter portioning and temporal biomass distribution.

Sadeghian et al. (2004) reported the effect of water deficit stress on germination and early seedling growth in sugar beet. In their study they used different concentration $(0.0,0.2,0.3 \mathrm{M})$ of mannitol on sugar beet. They suggest that drought stress could be induced by mannitol solution and they found significant differences between stress levels for seedling characteristics. At higher concentration of mannitol seedling growth and germination rates severely decreased.

Juhasz et al. (1997) conducted an experiment on bean (Phaseolus vulgaris L.) callus and seedling cultures to investigate non-ionic osmotic stress. They investigated the effect of mannitol-induced drought stress on bean seedling culture growth in this experiment. According to their findings shoot weight, root weight and root: shoot ratio all are decreased to a greater extent in sensitive seedlings than in tolerant ones when treated with mannitol.

Boutraa et al. (2010) investigated the impact of water stress on wheat cultivar growth and water usage efficiency (Al-gaimi, Sindy-1, Sindy-2 and Hab-Ahmar). Drought stress was induced in this experiment using mild $(50 \%)$ and severe $(30 \%)$ water deficit regimes with an 80 per cent soil field capacity control. Sindy-2 and HabAhmar were affected by slight water stress, although Al-gaimi was unaffected.

(Ghassemi-Golezani et al., 2008) conducted studies to see how water stress affected plant height, fresh and dry biomass, seed output, and essential oil content of dill during vegetative and reproductive stages (Anethum graveolens L.).The results of this experiment revealed that increasing water stress in dill plants reduced plant height, fresh and dry biomass, and seed yield yield like Plant height $(\mathrm{cm})$ was $78.07 \mathrm{a}, 62.69 \mathrm{~d}, 54.48 \mathrm{e}, 70.25 \mathrm{~b}$, $65.75 \mathrm{c}$, Fresh biomass $\left(\mathrm{g} / \mathrm{m}^{2}\right)$ was1950.0a, 856.1d, $580.6 \mathrm{e}, 1446.0 \mathrm{~b}, 1170.0 \mathrm{c}$, Dry biomass $\left(\mathrm{g} / \mathrm{m}^{2}\right)$ was 
421.4a, 220.0c, 144.6d, 310.3b, 252.0c and seed yield was $175.40 \mathrm{a}, 152.90 \mathrm{~b}, 130.30 \mathrm{c}, 114.80 \mathrm{~d}, 89.99 \mathrm{e}$, respectively. In this experiment their results showed that increasing water stress condition in dill plants decreased the plant height, fresh and dry biomass and seed yield like plant height $(\mathrm{cm})$ was $78.07 \mathrm{a}, 62.69 \mathrm{~d}, 54.48 \mathrm{e}, 70.25 \mathrm{~b}$, $65.75 \mathrm{c}$, fresh biomass $\left(\mathrm{g} / \mathrm{m}^{2}\right)$ was $1950.0 \mathrm{a}, 856.1 \mathrm{~d}, 580.6 \mathrm{e}$, $1446.0 \mathrm{~b}, 1170.0 \mathrm{c}$, dry biomass $\left(\mathrm{g} / \mathrm{m}^{2}\right)$ was $421.4 \mathrm{a}, 220.0 \mathrm{c}$, $144.6 \mathrm{~d}, 310.3 \mathrm{~b}, 252.0 \mathrm{c}$ and seed yield was $175.40 \mathrm{a}$, $152.90 \mathrm{~b}, 130.30 \mathrm{c}, 114.80 \mathrm{~d}, 89.99 \mathrm{e}$, respectively. The study has investigated that under severe water stress condition plant observed highest reduction in height and biomass during vegetative stage, similarly seed loss in seed yield found during flowering and seed filling phases. Under all irrigation treatments, it was discovered that the essential oil concentration of seeds and flowers was higher than that of vegetative components. The amount of essential oil in dill flowers and seeds increased as the severity of the water shortage increased, with moderate water stress yielding the largest essence output per unit area. As a result of their findings, they suggested that a moderate water stress during the flowering and seed filling phases of dill could boost essential oil yield.

Grzesiak et al. (1996) used mannitol-induced drought stress to screen for varietal differences in seed germination and seedling growth in order to categorise the resistance of different legume plants (field bean, soybean, field pea and lupine) to water stress. They employed mannitol solution, which had a considerable impact on seed germination (both final and preliminary germination) and seedling growth parameters (seedling, dry matter of shoot and root). They divided the cultivars into two categories: drought resistant and drought susceptible. The estimation of direct effects of soil drought on seed output in a field experiment was used to rate drought tolerance of legume plants in laboratory testing.

In a pot trial (Davatgar et al., 2009) investigated the physiological and morphological responses of a semi dwarf rice (Hashemi cultivar) to different water stress intensities at different treatments. Plant height, number of panicles per hill, and delayed flowering were all significantly reduced ( $\mathrm{P} 0.05)$ under extreme water stress. However, the effect of water stress at different developmental stages reduced the grain yield due to unfilled grains.

In contrast to this root weight was highest under mild water stress at 50 per cent of flowering which was followed by severe water stress at mid-tillering. Results showed that leaf developmental and transpiration rates have the same sensitivity to water stress. According to their findings, the Hashemi cultivar is more susceptible to both mild and severe drought stress during the reproductive stage.

(Ahmed and Suliman, 2010) studied the effect of water stress on seed output and water-use efficiency in cowpea at various stages of growth. The reproductive stage of the cowpea is more vulnerable to water stress than the developing stage. In all three cowpea genotypes, seed yields were reduced by at least $50 \%$. Cowpea genotypes, on the other hand, produced better results at vegetative stage during water stress condition. Cowpea genotypes, on the other hand, performed better throughout the vegetative stage under the stress situation.

Their findings revealed that a decrease in seed yield is linked to a decrease in the number of harvested pods per plant, the number of seeds per pod and seed size. They discovered a significant difference in drought resistance between cowpea genotypes and those used to maximise the number of pods and seeds characteristics for maintaining stable and large seed yields under stress.

Assefa et al. (2013) investigated the agromorphological, physiological and yield-related performance of finger millet [Eleusine coracana (L.) Gaertn.] accessions evaluated for drought tolerance in the field. In terms of their sensitivity to water stress, the study shows that genotypes gathered from various locations had a wide range of responses to drought stress. Based on agro-morphological, physiological, and yieldrelated criteria, 23 of the 96 accession were selected as drought tolerant. Early maturing accessions (230107, 230108,230106 with $105.6 \mathrm{~cm}, 103.6 \mathrm{~cm}$, and $99.4 \mathrm{~cm}$, respectively) were found to be taller than late maturing accessions (238325, AAUFM-41 and 216046 with plant heights of $56.7 \mathrm{~cm}, 52.1 \mathrm{~cm}$ and $67.2 \mathrm{~cm}$, respectively). They also discovered the shortest plants, such as accessions 215982 and 215985 , which were $36.4 \mathrm{~cm}$ and $36.8 \mathrm{~cm}$ tall, respectively. For most physiological, morphological, and yield-related variables such as Chlorophyll Content Index (CCI), RWC in the leaf, green leaf number (GLN), green leaf area (GLA), ear number (EN), ear length (EL) and relative water content (RWC), differences were detected between accessions.RWC was highest in three accessions, 215985, AAUFM-6 and 215989 , with $100 \%, 98.6 \%$ and 93.7 per cent, respectively, as well as yield-related indices including tiller number (TN), productive tillers (PT), seed weight per head and per plant.They designated 23 accessions as 
drought tolerant based on high RWC, CCI, GLN, PT, EL and EN, as well as grain yield per head and per plant.

\section{Because of the low state pressure, drought stress substantially inhibits cell development:}

Drought stress greatly suppresses cell growth because of the low state pressure. Diffusion regulation will alter the upkeep of cell state for survival or assist plant growth beneath severe drought conditions in Pennisetum americanum (Shao et al., 2008). Bhatt and Srinivasa (2005) revealed that the reduction in plant height is related to a decline within the cell enlargement and additional leaf senescence under water stress. Development of optimum leaf space is very important to chemical action and dry matter yield. Water deficit stress largely reduced leaf growth and successively the leaf areas in several species of plant-like genus Populus (Wullschleger et al., 2005), soybean (Zhang et al., 2004) and lots of different species (Farooq et al., 2009). Important interspecies variations between 2 sympatric genus Populus species are found during a total range of leaves, total leaf space biomass in drought stress (Wullschleger et al., 2005). The leaf growth is additionally sensitive to water stress in wheat than in maize (Sacks et al., 1997), cowpea plant (Manivannan et al., 2007) and flower (Manivannam et al., 2008).

Some anatomical properties connected to parenchymatous cells, diameter of tracheas belonging to the root, stem, and leaf; stomata index and size and average number of stomata and epidermal cells were shown to be important characters altering in soybean plants under stress (Makbul et al., 2011). These traits were statistically significant as well.Root: shoot ratio increased during the drought period, reaching 1.51 in unstressed plants and 2.04 at the end of the drought period, total chlorophyll content was 2.11 in Unstressed plants and 1.52 in stressed plants, and stoma content was 2.11 in unstressed plants and 1.52 in stressed plants, and stomal conductance content was 2.11 in unstressed plants and 1.52 in stressed plants. In stressed plants, leaf, total chlorophyll content and stomatal conductance were reduced, whereas the root: shoot ratio was larger than in unstressed plants. Drought stress caused various morphological and physiological alterations in soybeans, according to the findings.

\section{Effects on photosynthesis and chlorophyll content:}

Photosynthesis is one of the most sensitive aspect to water shortages. Plants can withstand water stress by rearranging the functional and structural components of their photosynthetic machinery. Photosynthesis diminishes when the relative water content and leaf water potential decrease in higher plants. Water stress causes a decrease in photosynthesis, which leads to stomatal restriction and metabolic impairment in plants. Many studies have established that stomatal closure is caused by the reduction of $\mathrm{C} 4$ photosynthesis during water stress, whereas others have determined that non-stomatal variables play a significant role in stomatal closure. Under drought conditions, the photosynthetic rate of leaves in both $\mathrm{C} 3$ and $\mathrm{C} 4$ plants decreases.

There are various co-factors that reduce plant photosynthesis when they are under water stress. Low $\mathrm{CO}_{2}$ uptake due to stomatal closure and resistance and poor assimilation rates in photosynthetic leaves are the most conspicuous qualitative and quantitative changes seen in photosynthesizing pigments. At low water potential, assimilation rates in photosynthetic leaves are reduced due to reduced photosynthetic metabolites, enzyme activity, low carboxylation efficiency and impede chloroplast activity.

Zhao et al. (2020) conducted an experiment in winter wheat to see how water stress affected photosynthesis, yield and water usage efficiency. Drought stress was applied in four different sets in this experiment: $30-40$ per cent (severe stress), 40-50 per cent (moderate stress), 50-60 per cent (light stress) and 60-80 per cent (well-watered). Their findings revealed that under moderate and severe drought conditions, seasonal fluctuations in photosynthetic indices such as net photosynthetic rate $(\mathrm{Pn})$, intercellular carbon concentration ( $\mathrm{Ci})$, stomatal conductance (Gs), and transpiration (E) are dramatically reduced.

Chlorophyll content is an important indicator of photosynthetic activity, stress and nutritional status in plants. Generally, it is observed that healthy plants have higher chlorophyll content instead of unhealthy plants growing in same time interval. So, studies are carried on leaf chlorophyll content and its relationship with plant stress and its nutrition are important for improving agricultural practices (Liu et al., 2010).

The loss of chlorophyll was caused by the disintegration of chloroplasts and the disappearance of thylakoid structures (Cornoy et al., 1988). Chlorophyll is the most significant photosynthetic pigment that transforms light into energy and is utilised by plants to generate glucose from $\mathrm{CO}_{2}$ and water. The amount of chlorophyll in a plant determines its vigour and ability to 
photosynthesise (Carter and spiering, 2002). Severe drought stress has been observed to reduce photosynthesis rate in plants by altering chlorophyll components and damaging the photosynthetic system, according to multiple studies (Iturbe-Ormaetxe et al., 1998). According to (Smirnoff, 1995), a decrease in chlorophyll content under drought stress may result in active oxygen species damaging chloroplasts.

The leaf chlorophyll content decreases as the intensity of water stress increases in plants and the chlorophyll a/b ratio tends to increase (Zhu and Huang, 1994). Water stress inhibited biosynthesis of the precursor of chlorophyll in wheat leaves, according to Makhmudov (1983), resulting in a reduction in chlorophyll content. Photosynthetic pigments are important in the harvesting of light and the disposal of surplus energy in plants. Both chlorophyll $\mathrm{a}$ and $\mathrm{b}$ alter during drought stress, according to (Farooq et al., 2009).

Zlatev and Lidon (2005) investigated the water deficit impacts on plant growth, water relations and photosynthesis. In this experiment the drought stress impacts on plants decreased in photosynthetic carbon assimilation and growth. Plants have evolved a number of adaptive mechanisms of adaptation that allow that the biochemical system to screen with increased water deficit.

An experiment was conducted by Singh et al. (2018) to see the evaluation of morphological and physiological parameters during drought stress in barnyard millet (Echinochloa frumentacea) growing in Kumaun region of Himalayan. This experiment is evaluated to improve the yield of barnyard millet in harsh environmental conditions. In this experiment different parameters are taken such as RWC, moisture content, fresh weight, dry weight, chlorophyll a and chlorophyll b.

Ghorbanli et al. (2013) conducted studies on the impact of water stress on chlorophyll $\mathrm{a} / \mathrm{b}$, protein, proline, ascorbate and dehydroascorbate in two tomato species, viz., Akri and Mobil. Seeds were grown under greenhouse condition at $23^{\circ} \mathrm{C}$ with irrigation in control condition, mild drought condition and severe drought stress condition. Leaf stem and roots are observed after nine weeks of sowing. The results revealed increasing proline amount under mild and severe water stress conditions in roots, while in leaf and stem it increased in severe drought condition.

However, there are many other studies have also shown that under drought stress condition, photosynthesis decreases and attributed to perturbations of the biochemical processes (Lauer and Boyer, 1992).

Anjum et al. (2003) reported water stress in barley (Hordeum vulgare L.). subjected seedlings of the two cultivars of barley, Jau-87 and S-84728 to water stress by with-holding water irrigation. Their results showed that Chlorophyll a and total chlorophyll in leaves of either cultivar or chlorophyll $b$ in leaves of Jau-87 were found suppressed but chlorophyll b content of S-84728 was enhanced to some extent.

Hola et al. (2007) did an experiment to see how maize (Zea mays L.) inbreds and hybrids recovered from cold stress of varying durations: photosynthetic and antioxidant enzymes. They used chlorophyll content measurements to compare the responses of two maize inbred lines and their $F_{1}$ hybrid to chilling periods of varied lengths $(1,2,3$, or 4 weeks). Their findings revealed that plants exposed to 3 or 4 weeks of chilling had lower chlorophyll content than plants exposed to 1 or 2 weeks of chilling.

Osmolyte accumulation, photosynthetic pigment, and growth of Setaria italica (L.) P. Beauv., according to (Ajithkumar et al., 2013). Drought-stricken area they induced water stress in this experiment by irrigating every day (control), 4, 7, 10, and 13 days. Their findings revealed that in all treatments, shoot length and chlorophyll pigment decreased, whereas in the control condition, plant maturity rose. According to their findings, shoot length, photosynthetic pigments of chlorophyll, and root length all decreased when root length grew.

\section{Effect of drought stress on relative water content (RWC) : \\ Relative water content is considered as an} alternative measure to check water stress in plants. According to (Nagy et al., 1995 and E1 Hafid et al., 1998) there are many genotypic variations of RWC of several stressed crop plants were found. In many research's droughts stress and salt stress results a significant decrease in RWC in wheat.

RWC decreases progressively with increasing level of water stress in wheat and barley seedlings were evident from the studies of (Dalmia et al., 2004 and Teulat et al., 1997). Gaxiola et al. (2001) reported leaf relative water content (RWC) was used as a measure of plant water status to induce severe water stress. Under drought stress condition relative water content significantly decreases in all cultivers used in accordance with (Allahmoradi et al., 2011) in mungbean, 
(Mohammadkhani and Heidari, 2008) in maize (Moaveni, 2011) and (Farshadfar et al., 2011) in wheat.

In Saudi Arabia, Aref et al. (2014) studied the impact of water stress on the relative water and chlorophyll content of Juniperus Procera Hochst. Ex Endlicher. They separated the seedlings into saplings, mature and over-mature in their experiment. The results demonstrated that water stress reduced the RWC of needles substantially, with the effect being more obvious in older trees compared to seedlings.

\section{Impact of drought stress on chemical action and respiration:}

Water stress influences many changes in the physiological, organic chemistry and molecular part of chemical action. Water stress will induce chemical action either through stomatal closure or by means of pathway regulation (Chaves et al., 2003 and Flexas et al., 2004) or by guiding impairing metabolic activities. The most common metabolic changes are decreased ribulose bisphosphate (RuBP) and ribulose one, 5 bisphosphate carboxylase/oxygenase (Rubisco) macromolecule content (Bota et al., 2004), faded Rubisco activity (Parry et al., 2002), nucleotide synthesis impairment and photophosphorylation or faded inorganic phosphorus (Cronic, 2000). There's evidence in respect of some of the species that non-stomatal inhibition may take place first, leading to a brief increase in internal carbonic acid gas concentration ( $\mathrm{Ci}$ ) that causes stomata to shut. Recent studies counsel that each distributive limitation through stomatal nearer and non-stomatal limitation (such as aerobic harm to chloroplast) square measure to blame for the decline in chemical action under stress (Zhou et al., 2007).

Respiration under water stress is comparatively less understood. The importance of comprehending these responses cannot be overstated. Mitochondrial respiration is essential for the expansion and survival of plants (Gifford, 2003). The studies relating to water stress effects on respiration are restricted inspite the importance of the respiration (Ribas et al., 2005). Temperature is one of the major determinants affecting mitochondrial respiration. Respiration would increase exponentially with increasing temperatures from $0^{\circ}$ to $35^{\circ}-40^{\circ} \mathrm{C}$, reaching up at $40^{\circ} \mathrm{C}-50^{\circ} \mathrm{C}$. Temperature above $50^{\circ} \mathrm{C}$, leads to decreased respiration which is due to harm to the mechanism of metabolism. Water stress may end up in faded leaf and root respiration (Byrla et al., 2001). Root respiration rates are faded under drought stress conditions, which has been revealed through a greenhouse effect related study carried out by Byrla et al. (2001).

\section{Effects of water stress on plant biochemistry: Effect of drought free proline accumulation:}

Proline is an essential chemical molecule for plant osmotic stress tolerance. It is an osmolyte that increases in response to drought stress, assisting the plant in surviving the drought. Drought stress is monitored using proline accumulation as a criterion. The accumulation of compatible solutes like proline, glycine betaine and sucrose contribute to osmotic adjustment, prevention of protein denaturation, preservation of enzyme structure and activity and protection of membranes from damage by reactive oxygen species (ROS). In plants accumulation of free proline is regarded as a general response to stresses of different origin. According to (Chan et al., 1964; Barnett and Naylor, 1956 and Singh et al., 1973) free proline was found to be increased under water and osmotic stress.

Dobslaw et al. (1988) investigated accumulation of proline under cold stress conditions as a selection index for frost tolerance ranking in barley genotypes. Their results showed that most tolerant varieties like Odesskii 31, Pamina and dominator varieties reached their maximum proline content as early as 7 days after the onset of cold stress, while the four indicator varieties took 14-17 days to reach a maximum.

Heerden and Kruger (2002) studied drought stress and dark chilling effects on photosynthesis, proline accumulation and antioxidant metabolism in soyabean. Their results showed that stress tolerant cv. Maple arrow accumulates higher proline than sensitive cv. Fiskeby V under drought and chilling stress.

A systematic study has been carried by Chandrasekar et al. (2000) studied the physiological and biochemical responses of hexaploid and tetraploid wheat to drought stress. They found an increasing trend in proline accumulation under water stress condition. They observed that under water stress condition hexaploid cv. C-306 and Hira showed higher drought resistant than tetraploids HW 24 and A 9-30-1.

An experiment was conducted by Sairam and Dube (1984) to observed the effect of moisture stress on proline accumulation in wheat in relation to drought tolerance. They studied the extent of proline accumulation under water stress condition in 12 wheat varieties. Their results showed that varieties which accumulates more proline 
leads wilting symptoms at much lower soil water regime than those accumulate less proline.

Protsanke et al. (1975) observed the physiological and biochemical methods in drought and heat resistant cultivar of winter wheat and recorded increasing proline accumulation in drought and heat resistant wheat cultivar.

An experiment was conducted byRajgopal et al. (1977) toobserve Diurnal fluctuations in relative water content, nitrate reductase and proline content in water stressed and non-stressed wheat. They studied diurnal variations in proline content at $3 \mathrm{~h}$ intervals during a $24 \mathrm{~h}$ cycle in the flag leaf of wheat cultivar.

(Nath and Ghoshal, 1978) suggests that under water stress condition accumulation of proline content was used as a selection indexes for screening Triticum genotypes to identify their resistance. An experiment was conducted by Mohammad khani and Heidari (2008) to observe accumulation proline and soluble sugars and in two corn varieties that were induced by drought. Results also showed that proline concentration is more in shoots than in roots, but the concentration of soluble sugar was increased more in roots than in shoots.

A systematic study has been carried by (SimonSarkadi et al., 2006) to observe free amino acid changes in transgenic soyabean under water stress. In this experiment they determined that in water stress at higher temperature the increase in proline (pro) content in transgenic $(\mathrm{t})$ soyabean [Glysine $\max (\mathrm{L}$.$) merr. \mathrm{Cv}$. Ibis] plants over gene coding expression for last enzyme of pro biosynthesis, was considerably more han wild type (w) plants (105-fold versus 19-fold after 7 d). Habibi Ghader (2018) investigated that proline, soluble sugars, total phenolic and flavanoid contents increased under mild drought condition.

Water stress impact on oxidative damage and antioxidant enzyme activity in melon seedlings were explored by Kavas et al., (2013). In this experiment two melon seedlings were subjected with PEG 6000 solution. Results showed that proline accumulation in both seedlings increased with increased osmotic potential. CAT activity increased only at $-0.4 \mathrm{MPa}$ osmotic potential in both cultivars. PEG induced osmotic stress.

Munawarti et al. (2013) investigated the drought tolerance and proline accumulation of glagah (Saccharum spontaneum) accessions. They tested the effect of drought stress on plant height, stalk diameter, green leaf number, and leaf proline concentration of eight two-month-old glagah accessions during an eight-week period to determine their drought tolerance and to determine whether proline accumulation can be used as a metabolic marker of drought tolerance. The accessions BOT-53, BOT-54, and BOT-62 were shown to be the most tolerant and prolific under water stress. In droughtstressed plants, they discovered two distinct patterns of proline accumulation. After four and eight weeks of drought stress, proline content increased in four accessions, while proline content grew for four weeks and then fell in the remaining accessions. Their results revealed a substantial, positive connection between proline content after eight weeks and the number of green leaves following four weeks of drought.

Lum et al. (2014) observed the effect of drought stress on growth, proline and antioxidant enzyme activities of upland rice. This study was performed on eight rice varieties to evaluate drought stress at germination and early seedling growth stage. Results showed that proline accumulation and antioxidant activity were related with dry mass production. The antioxidant activity and proline accumulation increased in drought tolerant variety while it decreased in drought sensitive variety.

\section{Effect of drought on MDA content:}

Kotapati et al. (2014) in their experiment found response of antioxidative enzymes and lipoxygenase to drought stress in the leaves of finger millet. MDA and proline level recorded high increase in finger millet leaves. SOD, CAT, APX and GR raised activities with drought stress.

A systematic study has been carried by Wang et al. (2006) to observe the responses of photosynthetic functions to low temperature in flag leaves of rice genotypes at the milky stage. Remarkable increase in MDA content in rice genotypes was noticed as increasing duration of low temperature. Wang et al. (2006) observed the influence of low temperature stress on camellia species on two physiological indexes related to resistance to coldness. The MDA content increased remarkably with decreasing temperature in both the species was noticed.

Water stress consequences on the lipid peroxidation and antioxidant enzyme activities in two Brassica napus cultivars were investigated by Mirzaee et al. (2013). Different concentrations of PEG $6000(0,5,10$, and $15 \%$ (w/v) in 12 days old seedlings of two Brassica cultivars (SLM046 and Hyola 308) were taken up. After treatment of PEGin both cultivars of canola seedling, acontent of Malondialdehyde (MDA) is increased.

Kavas et al. (2013) observed the effect of drought 
stress on oxidative damage and antioxidant enzyme activity in melon seedlings. They subjected the two melon cultivars (Kýrkaðaç and Galia) to PEG-6000 solutions of 2 different osmotic potentials, $-0.2 \mathrm{MPa}$ and -0.4 MPa. MDA significantly increased in Kýrkaðaç at -0.4 MPa osmotic potential then Galia.

An experiment was conducted by Xu et al. (1995) to observe the membrane injury and lipid peroxidation in wheat leaves under drought stress by with-holding irrigation in pot experiment. They observed that MDA content was increased remarkably in these plants. They also noticed that theinte rference of soluble sugars in wheat leaves estimation suffered by the absorption spectra of MDA.In their experiment they concluded that lipid peroxidation might not be primary cause of drought injury to cell membrane in plant tissues.

Guo et al. (2006) reported the differential responses of antioxidative system to chilling and drought in four rice cultivars differing in sensitivity. They studied MDA content in four rice cultivars, two of them (Xiangnuo no. 1 and Zimanuo) cultivars were found tolerant against chilling but sensitive to drought condition and the other two (Xiangzhongxian no. 2 and IR50) were tolerant to droughtbut sensitive to chilling stress. Their results also showed that under drought elevated level of MDA content in Xiangzhongxian no. 2 and IR50 was found lower than those in Xiangnuo no. 1 and Zimanuo.

Zhang et al. (2000) conducted an experiment aimed at observing the effect of drought stress on physiological characters of leaves and seed-filling characteristics of the new wheat cultivar Yumai 36 during the late development stage. They compared MDA content in two wheat cultivars and their results showed that cultivar yumi 36 had lower MDA content than Yumi 8.

\section{Effect of drought on ascorbate content:}

Paciolla and Tommasi (2003) reported the ascorbate system in two bryophytes: Brachythecium velutinum and Marchantia polymorpha. They found that ascorbate content declined in liverwort while it was maintained in the moss after water stress. They also observed that ascorbate recycling is more efficient in the moss than in the liverwort. At last, they suggest a correlation between efficiency of ascorbate recycling and water stress tolerance.

Lascano et al. (2001)in their experiment found response of antioxidant system response of different wheat cultivars under drought: field and in vitro studies. They found an increase in ascorbate content and less oxidative damage in tolerant cv. namely Elite and La paz than to sensitive cv. viz., Oasis and Cruz alta.

\section{Effect of drought on hydrogen peroxide content:}

Abass and Mohamed (2011) reported the allevation of adverse effects of drought stress on common bean (Phaseolus vulgaris L.) by exogenous application of hydrogen peroxide. In this experiment they pre-treated the seeds by hydrogen peroxide $\left(\mathrm{H}_{2} \mathrm{O}_{2}\right)$ and observed its effects on them. Their results showed that $\mathrm{H}_{2} \mathrm{O}_{2}$ helps in activation of antioxidants in seeds which persist in the plants to reduce the oxidative damage in plants under drought stress.

An experiment was conducted by Sharma and Dubey (2005) to study drought induces oxidative stress and enhances the activities of antioxidant enzymes in growing rice seedlings. In their experiment they grow rice seedlings under invitro drought stress of -0.5 and $0.2 \mathrm{MPa}$ for 24 hours. Their results showed that $\mathrm{H}_{2} \mathrm{O}_{2}$ concentration were found declined with increasing drought stress. According to the study of Kavas et al. (2013) the effect of drought on oxidative activity in two melons cultivar. Their results showed that $\mathrm{H}_{2} \mathrm{O}_{2}$ content grew linearly with increasing levels of drought stress in both melons cultivars. They also suggest that the accumulation of hydrogen peroxide content is higher in the leaf tissues of Galia than Kýrkaðaç was observed under both drought stress conditions, $-0.2(\mathrm{P} \leq 0.05)$ and $-0.4 \mathrm{MPa}$ osmotic potentials $(\mathrm{P} \leq 0.01)$. their results also showed that Hydrogen peroxide content was always significantly higher in Galia than in Kýrkaðaç.

\section{Effect of drought on catalase and peroxidase activity:}

Kotapati et al. (2014) in their experiment found response of antioxidative enzymes and lipoxygenase to drought stress in the leaves of finger millet. MDA and proline level recorded high increase in finger millet leaves. SOD, CAT, APX and GR raised activities with drought stress.

Kavas et al. (2013) investigated the effects of water stress on oxidative damage and antioxidant enzyme activity in melon seedlings (2013). PEG 6000 solution was applied to two melon seedlings in this experiment. The accumulation of proline in both seedlings increased as the osmotic potential increased. In both cultivars, CAT activity increased only at $-0.4 \mathrm{MPa}$ osmotic potential.

Mirzaee et al. (2013) studied Different concentrations of PEG $6000(0,5,10$ and $15 \%(\mathrm{w} / \mathrm{v})$ in 
12 days old seedlings of two Brassica cultivars (SLM046 and Hyola 308) were taken up. After treatment of PEGin both cultivars of canola seedling, acontent of Malondialdehyde (MDA) is increased. They suggest that in water stress condition antioxidant enzyme activities (Superoxide dismutase (SOD), Peroxidase (POD), Catalase (CAT) and Ascorbate peroxidase (APX) increases in both shoots and roots of both canola cultivars. In this experiment antioxidant enzymes activity was higher in SLM046 than Hyola 308 cultivar.

Sharma and Dubey (2005). Observed the activities of antioxidant enzymes viz., guaiacol peroxidase (GPX) in rice seedling under drought stress. Their result showed that under mild drought stressed condition plants had higher guaiacol peroxidase (GPX) activity than control plants but the activity declined at high level of water stress.

\section{Plant drought resistance mechanisms :}

Plants react and acclimatize under drought stress by inducting various morphological, biochemical, and physiological responses inducting various morphological, biochemical, and physiological responses. In plants drought tolerance is defined as the ability to grow, flower and show an economic return under an under-optimal water supply. The reactions of plants to water stress at different levels depend on the intensity and length of the stress, as well as on the development phase of the plant species. Stress resistance is divided into two categories in plants: stress tolerance and stress avoidance. Stress avoid ancemeans plant has the ability to maintain high water potential tissue under dry conditions, while a plant's drought tolerance is the stability it can maintain its normal functions even when tissue is low. Drought avoidance is usually achieved by morphological modifications of the plant, including reduced stomach conductance, lower leaf area, extensive root systems development and increased root-shooting ratios. Drought tolerance is obtained through physiological, biochemical and molecular mechanisms of specific cell and tissues including specific gene expression and accumulation of particular proteins. Plants acclimatize drought by fundamental changes through different in water relation, biochemical and physiologicalprocess, membrane structure, and ultrastructure of sub cellular organelles. In order to cope with the drought, tolerant plants initiate water deficit protection mechanisms (Chaves and Oliveira, 2004), which need further research (Zhou et al., 2007). Mechanisms of drought tolerance at various levels are presented in the following sections.

\section{Morphological mechanism in plants:}

Plant drought tolerance involves flora, tissue, physiology and molecular changes. The manifestation of one or a combination of inherent modifications determines the plant's ability to retain a limited amount of moisture. Plant accounts different morphological mechanisms under dry conditions such as escape, avoidance and Phenotypic flexibility.

Drought escape is achieved via a shorter life cycle or growing season, allowing plants to reproduce before the environment becomes dry. Flowering time is an important feature of adjusting drought, where a short cycle of life can lead to drought escape (Araus et al., 2002). Drought escape occurs when phenological development is successfully matched to soil humidity availability periods in which the growing season is shorter and a final drought stress prevails (Araus et al., 2002). Crop duration is determined by genotype and environment interactively and determines the ability of the crop to escape climatic stress, even drought (Dingkuhn and Asch, Dingkuhn). Some plants have mechanisms to mitigate drought stress in arid environments, such as stomach shut-outs, tissue partial senescence, leaf growth reduction, (Araus et al., 2002) development of water storage organs and increased root length and density, in order to make the use of water more efficient.

Avoidance of droughts in plants consists different mechanisms to reduce water loss from plants, by stomatal control in transpiration as well as maintain a large, prolific root system for absorption of water (Turner et al., 2001 and Kavar et al., 2007). The main drought prevention traits that help in the final yield in terminal drought environments are root characters such as biomass, length, density and depth (Subbarao et al., 1995 and Turner et al., 2001). A thick and deep-root system is useful in the extraction of water from significant depths (Kavar et al., 2007).

Plant growth is majorly affected by water stress. Root and shoot are the most affected parts in plants and are the two main components for adaption to drought. Plants generally limit the number and area of leaves due to drought stress, only to reduce the budget for water at the expense of yield loss (Schuppler et al., 1998). As roots are the only source of soil water, root growth, density, proliferation and size are important plant reactions to drought stress (Kavar et al., 2007). 


\section{Physiological mechanism in plants:}

Drought tolerance was aided by osmotic adjustment, osmo-protection, antioxidation, and a scavenging defence system. Osmotic adjustment can lower the cell's osmotic potential, increasing the water flow gradient and maintaining turgor. Osmotic adjustments and/or changes in cell wall flexibility can improve tissue water status. It has been found that osmotic adjustment, abscisic acid and induction of dehydrins can confer drought tolerance between different mechanisms by maintaining a high tissue water potential (Turner et al., 2001). The cell's osmotic potential is reduced by the accumulation of solutes which attracts water to the cell and helps in the maintenance of turgor.

Furthermore, the osmotic adaptation makes it possible to better translocate pre-anthesis carbohydrate separation during the filling of grain (Subbarao et al., 2000), whereas high turgor maintenance leads to greater photosynthesis rate and growth (Subbarao et al., 2000).

The defence against antioxidants in the plant cell constitutes both Enzyme and non-enzyme components. Enzymatic compounds contain Superoxide dismutase, catalase, Butxidase, ascorbate peroxidase and reductase glutathione. Non-enzymatic components includecysteine, glutathione reduced Acid of ascorbics and (Gong et al., 2005). Within the environmentStress tolerance like drought, high antioxidant enzymaticactivity and nonenzymatic constituents are important. It was found that Proline is the largest distributed osmolyte and accumulates not just in high plants but also in eubacteria, protozoa, marine invertebrates and algas under stressful conditions (Delauney and Verma, 1993). Proline synthesis may serve as a means for absorbing excess nitrogen in the storage and conservation of nitrogen (Brugiere $e t$ $a l .$, 1999). Catalase (CAT), dismutase superoxide (SOD), peroxidases (POD), ascorbate peroxidases (APX), glutathione reducctase (GR) and reductase monodehydroascorbate (MDAR) are prominent among antioxidant enzymes. In addition to antioxidant molecules such ascorbic acid (AA), glutathione, flavanones, tocophereals, carotenoids and anthocyanins. Antioxidants also act as ROS-scavenger with certain components like osmolytes (e.g., prolines), proteins (e.g., peroxiredoxins) and amphiphile molecules such as tocopherols.

In plant tissue oxidative damage is alleviated by a concerted action both by enzyme and non-enzyme antioxidant systems. They include $\beta$-carotenes, acidascorbic, stocopherol, reduced glutathione and enzymes including dismutase-superoxide, peroxidase, ascorbate peroxidase, catalase, oxidase-polyphenol and reductaseglutathione (Hasegawa et al., 2000 and Prochazkova et al., 2001). Plant's growth regulators are substances which affect the physiological process of plants with very low concentrations when used externally and phytohormones are produced internally (Morgan, 1990). Drought normally reduces the endogenous content of auxins, gibberellin and cytokine, while abscisic acid and ethylene tend to increase (Nilsen and Orcutte, 1996). However, phytohormones play important rolesin drought tolerance of plants.

\section{Conclusion:}

The changing climatic conditions all over the world under the influence of global warming often take unusual weather events form water stress or water flood condition. In plants drought is severe due to prolonged exposure of water stress. Plants have developed innate mechanism for controlling water stress via the evolutionary mechanism.

The literature analysed in this review demonstrates the complexity of tolerance to water stress and also supports many authors' statements that cell metabolism flexibility and its adherence to environmental changes represent an important first step in stress prevention (Yordanov et al., 2000). Due to the sessile life cycle, plants developed mechanisms to react and adapt during their development and development to adverse environmental stresses. This review focused on the morphological and physiological mechanisms involved in the response of the plant to water stress and the subsequent adjustment of growth. These mechanisms include stomach reactions, Ion transport, stress signal activation and photosynthesis protection reactions. Understanding these important factors allows us to improve the productivity of plants during water stress. It was adapted from genetic machineries, which aid plants in producing enzymes, proteins, and synthesising molecules which are appropriate to combat water shortage in various ways. The oxidative stress caused by drought is also addressed by plant synthesiser of bio molecules.

Our study of the causes and effects of water stress on plants, as well as plant responses in diverse ways, has already resulted in the development of a biotechnological procedure to improve the drought adaptability of fewer adaptive plants. However, there are still many dark areas of our knowledge of causes and impacts of the water stress in plant and we need to 
enhance our appreciation of the issue.

\section{REFERENCES}

Ahmed, A. M., Heikal, M. M. and Zidan, M. A. (1980). Effect of salinization treatments on growth and some related physiological activities of some leguminous plants. Plant Sci., 60 : 713-720.

Ahmed, F. E. and Suliman, A.S. H. (2010). Effect of water stress applied at different stages of growth on seed yield and water-use efficiency of Cowpea. Agric. Biol. J. of North America, 1(4) : 534-540.

Ainsworth, E.A., Leakey, A.D.B., Ort, D.R. and Long, S.P. (2008). Facing the facts: inconsistencies and inter dependence among field, chamber and modeling studies of elevated $\left(\mathrm{CO}_{2}\right)$ impacts on crop yield and food supply. New Phytol., 179 : 5-9.

Ajithkumar, I. P. and Panneerselvam, R. (2013). Osmolyte accumulation, photosynthetic pigment and growth of Setaria italica (L.) P. Beauv. under drought stress. Asian Pacific J. Reproduction, 2 (3) : 220-224.

Ajithkumar, I.P. and Panneerselvam, R. (2013). Osmolyte accumulation, photosynthetic pigment and growth of Setaria italica (L.) P. Beauv. under drought stress. Asian Pacific J. Reproduction, 2 (3) : 220-224.

Alexieva, V., Sergiev, I., Mapelli, S. and Karanov, E. (2001). The effect of drought and ultraviolet radiation on growth and stress markers in pea and wheat. Plant Cell Environ., 24 : 1337-1334.

Anjum, F., Yaseen, M., Rasul, E., Wahid, A. and Anjum, S. (2003). Water stress in barley. I. Effect on chemical composition and chlorophyll content. Pakistan J. Agric. Sci., 40 : 45-49.

Anjum, F., Yaseen, M., Rasool, E., Wahid, A. and Anjum, S. (2003). Water stress in barley (Hordeum vulgare L.) II. Effect on chemical composition and chlorophyll content. Pak. J. Agric. Sci., 40 : 45-49.

Araus, J. L., Slafer, G. A., Reynolds, M. P. and Royo, C. (2002). Plant breedingand drought in C-3 cereals: what should we breed for? Ann. Bot., 89 : 925-940.doi: 10.1093/aob/mcf049.

Assefa, A. and Fetene, M. (2013). Agro-morphological, physiological and yield related performances of finger millet [Eleusine coracana (L.) Gaertn.] accessions evaluated for drought resistance under field condition. Asian J.Agric. \& Rural Develop., 3 (10): 709-720.

Begg, J.E. and Turner, N.C. (1976). Crops water deficits. $A d v$. Agron., 28:161.
Benhin, J.K.A. (2008). South African crop farming and climate change: An economic assessment of impacts. Global Environ. Change, 18 : 666-678.

Benjamin, J.G. and Nielsen, D.C. (2006). Water deficit effects on root distribution of soybean, field pea and chickpea. Fields Crop Research, 97: 248-253.

Bonham, G.A., Dullo, E., Mathur, P., Brahmi, P., Tyagi, V., Tyagi, R.K. and Upadhyaya, H. (2010). Plant genetic resources and germplasm use in India. Asian Biotech. Dev. Rev., 12 : 17-34.

Borlaug, N. E. and Dowswell, C. R. (1993). Fertilizer: To nourish infertile soil that feeds a fertile population that crowds a fragile world. Fert.News, 387 : 11-20.

Boutraa, T., Akhkha, A., Al-Shoaibi, A.A. and Alhejeli, A.M. (2010). Effect of water stress on growth and water use efficiency (WUE) of some wheat cultivars (Triticum durum) grown in Saudi Arabia. JTUSCI, 3: $39-48$.

Boyer, J.S. (1982). Plant productivity and environmental potential for increasing crop plant productivity, genotypic selection. J. Sci., $218: 443-448$.

Cakmak, I. (2002). Plant nutrition research: Priorities to meet human needs for food in sustainable ways. Plant Soil., 247: 3-24.

Carter, A.G. and Spiering, B. A. (2002). Optical properties of intact leaves forestimating chlorophyll concentration. J. Environ. Qual., 31:1424-1432.

Chandrasekar, V., Sairam, R.K. and Srivastava, G.C. (2000). Physiological and biochemical responses of hexaploid and tetraploid wheat to drought stress. $J$. Agro. Crop Sci., 185 : 219-227.

Chaves, M.M., Maroco, J.P. and Periera, J.S. (2003). Understanding plant responses to drought from genes to the whole plant. Functional Plant biol., 30 :239-264.

Chaves, M.M. and Oliveira M.M. (2004). Mechanisms underlying plant resilienceto water deficits: prospects for water-saving agriculture, J. Exp. Bot., 55 : 2365-2384.

Cornoy, J. P., Virgon, J. M., Smilie, R. M. and Barlow, E.W. (1988). Influence of drought acclimation and $\mathrm{CO}_{2}$ enrichment on osmotic adjustment and chlorophyll a florescence of sunflower during drought. Plant Physiol., 186: 1108-1115.

Darofeev, V.F. and Tyselano, A.M. (1982). Number of seminal roots in spring wheat in the course of selecting pair for hybridization. Vestnik Selokokhozysist., 8:50-56. 
Davatgar, N., Neishabouria, M.R., Sepaskhahb, A.R. and Soltani, A. (2009). Physiological and morphological responses of rice (Oryza sativa L.) to varying water stress management strategies. Int. J. Plant Produc., 3 (4): 19-32.

Dhanda, S.S., Sethi, G.S. and Behl, R.K. (2004). Indices of drought tolerance in wheat genotypes at early stages of plant growth. J. Agron. \& Crop Sci., 190: 6-12.

Dobslaw, S. and Bielka, S. (1988). Studies to establish frost tolerance ranking in winter barley by means of proline accumulation.1. Tests on indicator varieties. Arch. Zuchtungsforschung, 18: 235-240.

Eghball, B. and Maranville, J.W. (1993). Root development and nitrogen influx of corn genotypes grown under combined drought and nitrogen stress. Agron. J., 85 :147-152.

Epstein, E.J.D., Rush, R. W., Kingabury, D. B., Keiley, J. A. and Cinnigham, A. F. (1980). Saline culture of crops: a genetic approach, Science, 210 : 399-404.

Farooq, M., Basra, S.M.A., Wahid, A., Cheema, Z.A., Cheema M.A. and Khaliq, A. (2008). Physiological role of exogenously appliedglycinebetaine in improving drought tolerance of fine grain aromaticrice (Oryza sativa L.). J. Agron. Crop Sci., 194: 325-333.

Farooq, M., Wahid, A., Kobayashi, N., Fujita, D. and Basra, S. M.A. (2009). Plant drought stress: effects, mechanisms and management. Agron. Sustain. Dev., 29 : 185-212.

Ghassemi-Golezani, K., Andalibi, B., Zehtab-Salmasi, S. and Saba, J. (2008). Effect of water stress during vegetative and reproductive stages on seed yield and essential oil content of dill (Anethum graveolens L.). J. Food Agric. Environ., 6: 282-284.

Ghorbanli, M., Gafarabad, M., Amirkian, T. and Allahverdi Mamaghani, B. (2013). Investigation of proline, total protein, chlorophyll, ascorbate and dehydroascorbate changes under drought stress in Akria and Mobil tomato cultivars, Iran. J. Plant Physiol., 3 : 651-658.

Gruhn, P., Goletti, F. and Yudelman, M. (2000). Integrated nutrient management, soil fertility, and sustainable agriculture: current issues and future challenges. Food, Agriculture, and the Environment Discussion Paper 32, International Food Policy Research Institute, Washington, D.C., U.S.A.

Grzesiak, S., Filek, W., Skrudlik, G. and Niziol, B. (1996). Screening for drought tolerance: evaluation of seed germination and seedling growth for drought resistance in legume plants. J. Agro. Crop Sci., 177:
245-252.

Guo, Z., Ou, W., Lu, S. and Zhong, Q. (2006). Differential responses of antioxidative system to chilling and drought in four rice cultivars differing in sensitivity. Plant Physiol. Biochem., 44: 828-836.

Hanson, A. D. and Hitz, W. D. (1982). Metabolic responses of mesophytes to plant waterdeficits. Ann. Rev. Plant Physiol., 33: 163-203.

Heerden, P.D.R. and Kruger, G.H.J. (2002).Separately and simultaneously induced dark chilling and drought stress effects on photosynthesis, proline accumulation and antioxidant metabolism in soyabean. J. Plant Physio., 159 : 1077-1086.

Hola, D., Kocova, M., Rothova, O., Wilhelmova, N. and Benesova, M. (2007). Recovery of maize (Zea mays L.) inbreds and hybrids from chilling stress of various duration: photosynthesis and antioxidant enzymes. J. Plant Physiol., 164: 868-877.

IPCC (2007). Climate Change 2007: Impacts, adaptation and vulnerability. Contribution of working group II to the forth assessment report of the intergovernmental panel on climate change, Geneva, Switzerland.

Iturbe Ormaetxe, I., Escuredo, P. R., Arrese-Igor, C. and Becana, M. (1998). Oxidative damage in pea plants exposed to water deficit or paraquat. Plant Physiol., 116: 173181.

Iturbe Ormaetxe, I., Escuredo, P. R., Arrese-Igor, C. and Becana, M. (1998). Oxidative damage in pea plants exposed to water deficit or paraquat. Plant Physiol., 116: 173181.

Jaleel, C. A., P. Manivannan, A. Kishorekumar, B. Sankar, R. Gopi, R. Somasundaram, and R. Panneerselvam (2007). Alterations in osmoregulation, antioxidant enzymes and indole alkaloid levels in Catharanthus roseus exposed to water deficit, Colloids Surf. B: Biointerfaces, 59 : 150-157.

Jaleel, C.A., Gopi, R., Sankar, B., Gomathinayagam, M. and Panneerselvam, R. (2008a). Differential responses in water useefficiency in two varieties of Catharanthus roseus under droughtstress. Comp. Rend. Biol., 331: $42-47$.

Jaleel, C.A., Manivannan, P., Lakshmanan, G.M.A., Gomathinayagam, M. and Panneerselvam, R. (2008b). Alterations in morphological parameters and photosynthetic pigment responses of Catharanthusroseus under soil water deficits. Colloids Surf. B: Biointerfaces., 61: 298-303.

Jarvies, A., Upadhyaya, H., Gowda, C.L.L., Aggarwal, P.K., 
Fujisaka, S. and Andersen, B. (2011). Climate change and its effect on conservation and use of plant genetic resources for food and agriculture and associated biodiversity for food security. FAO Thematic Background Study. Available online: http:/ /www.fao.org/decrep/013/i1500e/i1500e16.pdf Accessed: September 202011.

Juhasz, G.A., Simon, S. L., Velich, I., Varro, P., Altman, A. and Ziv, M. (1997). Studies of non-ionic osmotic stress on bean (Phaseolus vulgaris L.) callus and seedlings cultures. Acta Horticulturae, 447 : 455-456.

Kage, H., Kochler, M. and Stützel, H. (2004). Root growth and dry matter partitioning of cauliflower under drought stress condi-tions: measurement and simulation. European J. Agron., 20 : 379-394.

Karthikeyan, B., Jaleel, C.A., Gopi, R. and Deiveekasundaram. (2007). Alternations in seedling vigor and antioxidant enzyme activitiesin Catharanthus roseus under seed priming with native diazotrophs. J. Zhejiang Univ. Sci., 8 (B) : 453-457.

Kramer, P.J. (1983). Plant water relation. Academic Press.New York, U.S.A.

Kumar, S.G., Reddy, A.M. and Sudhakar, C. (2003). NaCl effects on prolinemetabolism in two high yielding genotypes of mulberry (Morusalba L.) with contrasting salt tolerance, Plant Sci., 165 : 1245-1251.

Kurukulasuriya, P., Benhin, J. K.A. Deressa, T. (2006). Will African agriculture survive climate change? World Bank Economic Review, 20 (3) : 367-388.

Kusaka M., Lalusin, A.G. and Fujimuram, T. (2005). The maintenance of growth and turgor in pearlmillet (Pennisetum glaucum L. Leeke) cultivars with different root structures and osmoregulation under drought stress. Pl. Sci.,168 : 1-14.

Larcher, W. (1987). Stress $\beta$ bei pflanzen. Natur wissenschaften, 74 : 158-167.

Lascano, H.R., Antonicelli, G.E., Luna, C.M., Melchiorre, M.N., Gomez, L. D., Racca, R.W. Trippi, V.S. and Casano, L.M. (2001). Antioxidant system response of different wheat cultivars under drought: Field \& In vitro Studies, 28 : 1095-1012.

Levitt, J. (1980). Responses of plants to environmental stresses. 1, Acad. Press, 496pp.

Ludlow, M.M. and Muchow, R.C. (1990). A critical evolution of traits fo improving crop yields in water limited environments. Adv. Agron., 43:107-153.

Mahajan, S. and Tuteja, N. (2005). Cold, salinity and drought stresses: An overview. Arch. Biochem. Biophys. 444:
139-158.

Mahajan, S. and Tuteja, N. (2006). Cold, salinity and drought stresses. An overview; Arch. Biochem.Biophys., 444 :139-158.

Makbul, S., Güler, N. S., Durmu, N. and Güven, S. (2011). Changes in anatomical and physiological parameters of soybean under drought stress. Turk J. Bot., 35: 369-377.

Manivannan, P., Jaleel, C.A., Somasundaram, R. and Panneerselvam, R. (2008). Osmoregulation and antioxidant metabolism in drought-stressed Helianthus annuus under triadimefon drenching. Comp. Rend. Biol., 331 : 418-425.

Maqsood, M. and Azam Ali, S.N. (2006). Effects of environmental stress on growth, radiation use efficiency and yield of finger millet. Pak. J. Bot., 39 (2): 463-474.

Moaed Almeselmani (2011). Effect of drought on different physiological characters and yield component in different varieties of syrian durum wheat. J. Agric. Sci., 3 (3): 122-125.

Morison, J. I. L., Baker, N. R., Mullineaux, P. M. and Davies, W.J. (2008). Improving water use in crop production. Philosophical Transactions of the Royal Society BBiological Sciences, 363 : 639-658.

Munawarti, A., Taryono., Semiarti, E., Holford, P. and Sismindari (2013). Tolerance of accessions of glagah (Saccharum spontaneum) to drought stress and their accumulation of proline. American J. Agric. \& Biol. Sci., 8(1):1-11.

Naresh, R.K., Purushottam., Singh, S. P., Dwivedi, A. and Kumar, V. (2013). Effects of water stress on physiological processes and yield attributes of different mungbean (L.) varieties.Afr. J. Biochem. Res.,7(5) : 55-62.

Nath, S.B. and Ghoshal, K.K. (1978). Proline accumulation as a selection index for water stress resistance in triticum genotypes. Indian Agriculturist, 22 : 35-39.

Newton, A.C., Johnson, S.N. and Gregory, P.J. (2011). Implications of climate change for diseases, crop yields and food security. Euphytica., 179 : 3-18.

Ommen, O. E., Donnelly, A., Vanhoutvin, S., Van Oijen, M. and Manderscheid, R. (1999). Chlorophyll content of spring wheat flag leaves grown under elevated $\mathrm{CO}_{2}$ concentrations and other environmental stresses within the ESPACE-wheat project. Eur. J. Agron., 10: 197-203.

Paciolla, C. and Tommasi, F. (2003). The ascorbate system in two bryophytes: Brachythecium velutinum and 
Marchantia polymorpha. Biologia Plant, 47: 387393.

Pinstrup-Andersen, P., Pandya-Lorch, R., Rosegrant, M. W. (1999). World food propects: Critical issues for the early twenty-firstcentury. 2020 Vision Food Policy Report, International Food PolicyResearch Institute, Washington, D.C.

Praba, M. L., Cairns J. E, Babu, R.C and Lafitt, H. R., (2009). Identification of Physiological Traits Underlying Cultivar Differences in Drought Tolerance in Rice and Wheat.J. Agronomy \& CropScience, 195: 3046.

Protsenke, D.P., Kirichenko, F.G., Muaienko, N.N. and Slavnyi, P.S. (1975). Peculiarities of water status in winter wheat cultivars during ontogenesis in relation to drought and heat resistance. In : Vodoobmen Rastenii Pri Neblagopriyetnykh Usloviyakh Aredy, Kishinev, Moldavian SSR; 'shtiintsa'-33-38, c.f. Field Crop Abstr, 29 : 6228.

Rajagopal, V., Balasubramanian, V. and Sinha, S.K. (1977). Diurnal fluctuations in relative water content, nitrate reductase and proline content in water stressed and non-stressed wheat. Physiol. Plant, 40 : 61-71.

Rashidi, S., Rad, A.H., Band, A.A., Javidfar, F. and Lak, S. (2012). Study of relationship between drought stress tolerance with some physiological parameters in canola genotypes (B.napus L.). Annals of Biological Research, 3 (1):564-569.

Sadeghian, S.Y. and Yavari, N. (2004). Effect of water deficit stress on germination and early seedling growth in sugar beet. J. Agro. Crop Sci., 190 : 138-144.

Sairam, R.K. and Dube, S.D. (1984). Effect of moisture stress on proline accumulation in wheat in relation to drought tolerance. Indian J.Agric. Sci., 54 : 146-147.

Sarafis, V. (1998). Chloroplasts: a structural approach. J. Plant Physiol., 152 : 248-264.

Serraj, R., Krishnamurthy, K.L., Ashiwagi, J., Kumar, J., Chandra, S. and Crouch, J.H. (2004). Variation in root traits of chickpea (Cicer arietinum L.) grown under terminal drought. Field Crops Research,88 : 115-127.

Shao, H.B., Chu, L. Y., Jaleel, C. A. and Zhao, C. X. (2008). Water-deficit stress-induced anatomical changes in higher plants. ComptesRendus, 331 (3) : 215-225.

Sharma, P. and Dubey, R.S. (2005). Drought induces oxidative stress and enhances the activities of antioxidant enzymes in growing rice seedlings. Plant Growth Regu., 46 : 209-221.

Slayter, R.O. (1973). The effect of internal water status on plant growth, development and yield. In: Plant response to climatic factors. Slayter, R.O. (eds.). Proc. Uppsala Symp. UNESCO, Paris. pp. 177-191.

Smirnoff, N. (1995). Antioxidant systems and plant response to the environment. In: Smirnoff $V$ (Ed.), environment and plant metabolism: Flexibility and acclimation, BIOS Scientific Publishers, Oxford, UK. 65.

Somasundaram, R., Beemarao, S., Kumar, K. A., Panneerselvam, R., Heruth, C., Jaleel, A. and Manivannan, P. (2007). Drought induced esculentus (L.) Moench. Acta Bot. Croat., 66 : 43-56.

Subbarao, G.V., Johenson,C., Slinkard, A.E., Rao, R.C.N., Saxena, N.P. and Chauhan, Y.S.(1995). Strategies and scope for improving drought resistance in grain legumes. Crit. Rev. Plant Science, 14 : 469-523.

Talebi, R., Ensafi, M.H., Baghbani, N., Karami, E. and Mohammadi, K.H. (2013). Physiological responses of chickpea (Cicer arietinum) genotypes to drought stress. Environ. \& Exp. Biol., 11: 9-15.

Tin, T. (2008). Climate change, faster, stronger, sooner. A European update of climate science. http://assets. panda.org/downloads/wwf_science_paper_ october_ 2008.pdf.

Tuba, Z., H. K. Lichtenthaler, Z. Csintalan, Z. Nagy and K. Szente. (1996). Loss of chlorophylls, cessation of photosynthetic $\mathrm{CO}_{2}$ assimilation and respiration in the poikilochlorophyllous plant Xerophyta scabrida during desiccation. Physiol. Plant., 96 : 383-388.

Wang, J., Zhang, C., Chen, G., Wang, P., Shi, D. and Lu, C. (2006). Responses of photosynthetic functions to low temperature in flag leaves of rice genotypes at the milky stage. Rice Sci., 13: 113-119.

Wang, Y., Li, J., Tian, M. and Geriletu (2006). Influence of low temperature stress on camellia species two physiological index related to resistance to coldness. Forest Res., 19 : 121-124.

Xu, C., Zhao, S., Meng, Q., Peng, Tao, Zou, Qi, Xu, C.C, Zhao, S.J., Meng, Q.W., Peng, T and Zou, Q. (1995). Membrane injury and lipid peroxidation in wheat leaves under drought. J. Shandong Agric.Univ., 26: 412-418.

Yancey, P.H., Clark, M. E., Hand, S.C., Bowlis, R. D. and Sumero, G.N. (1982). Living with water stress: evolution of osmolyte system. Sci., 217:1214-1222.

Yasemin, E. and Tugce, K. (2005). The effect of drought on plants and tolerance mechanism. G. U. J. Sci., 18 : 723-740.

Yordanov, I., Velikova, V. and Tsonev, T. (2000). Plant 
responses to drought, acclimation and stress tolerance, Photosynthetica, 38 : 171-186.

Zhang, Q., Liu, H., Meng, F., Zhang, S., Zhang, Z. and Kang, G. (2000). The effect of drought stress on physiological characters of leaves and seed-filling characterstics of the new wheat cultivar Yumai 36 during the late development stage. Scient. Agricultur. Sinica, 33 : 94-96.

Zhang, W., Li, C., Qian, C. and Cao, L. (2009). Studies on the responses of root, shoot and drought resistance in the seedlings of forage triticale to water stress. $J$. Agric. Sci., 1 (2) : 50-57.
Zhao, C. X., Guo, L. Y., Jaleel, C. A., Shao, H. B. and Yang, H. B. (2008). Prospects for dissecting plant-adaptive molecular mechanisms to improve wheat cultivars in drought environments. Comptes Rendus Biologie, 331 : 579-586.

Zhou, Y., Lam, H.M. and Zhang J. (2007). Inhibition of photosynthesis andenergy dissipation induced by water and high light stresses in rice, J. Exp. Bot., $\mathbf{5 8}$ : 1207-1217.

Zhu, H.S. and Huang, P.S. (1994). Soil water stress and active oxygen metabolism in rice. J. Nanjing Agric. Univ., 17 (2) : 7-11. 